\title{
Perfilhamento, Área Foliar e Sistema Radicular do Capim-Mombaça Submetido a Combinações de Doses de Nitrogênio e Potássion
}

\author{
José Lavres Junior², Francisco Antonio Monteiro ${ }^{3}$
}

\begin{abstract}
RESUMO - Conduziu-se um experimento em casa-de-vegetação no período de novembro de 2000 a fevereiro de 2001 com o objetivo de avaliar os efeitos de combinações de doses de nitrogênio $(\mathrm{N})$ e potássio (K) quanto ao perfilhamento, área foliar e comprimento e superfície total e específica do sistema radicular de Panicum maximum Jacq. cv. Mombaça. Foi empregado um esquema fatorial $5^{2}$ incompleto, perfazendo um total de 13 combinações das doses de $\mathrm{N} \mathrm{e} \mathrm{K}$, as quais foram distribuídas segundo o delineamento experimental de blocos ao acaso, com quatro repetições. As plantas foram colhidas aos 36 dias após o transplante das plântulas e aos 29 dias após o primeiro corte, procedendo-se nesta ocasião, a separação das raízes da sílica, sendo em seguida lavadas. Os resultados evidenciaram interação significativa entre as doses de $\mathrm{N}$ e K na área foliar em ambos os cortes, no número de perfilhos por ocasião do segundo corte e no comprimento total e na superfície total de raízes. As doses de $\mathrm{N}$ e $\mathrm{K}$ tiveram influência significativa no perfilhamento do capim-mombaça por ocasião do primeiro corte. O comprimento radicular específico e a superfície radicular específica foram significativamente influenciados tanto pelo suprimento de $\mathrm{N}$ como de $\mathrm{K}$.
\end{abstract}

Palavras-chave: comprimento radicular específico, comprimento radicular total, Panicum maximum, raiz, superfície radicular específica, superfície radicular total

\section{Tillering, Leaf Area and Mombaçagrass Root System in Response to Nitrogen and Potassium Combinations}

\begin{abstract}
An experiment was carried out in a greenhouse from November 2000 to February 2001 with the objective of evaluating the effects of nitrogen $(\mathrm{N})$ and potassium $(\mathrm{K})$ rates on tillering, leaf area, total root length, total root surface, specific root length and specific root surface of Panicum maximum Jacq. cv. Mombaça. The forage grass was grown in nutrient solution using ground quartz as substrate. The experimental arrange used was an incomplete $5^{2}$ factorial of $\mathrm{N}$ and $\mathrm{K}$ and the 13 combinations between $\mathrm{N}$ and $\mathrm{K}$ were obtained according to design points of the modified central composite nonrotatable design that was set in a randomized block design, with four replications. Plants were harvested twice. The first harvest was at 36 days after transplanting and the second at 29 days after the first harvest. Following the second harvest, the roots were separated from ground quartz, collected and also washed. Results showed that $\mathrm{N}$ x K interaction was significant for leaf area at both harvest, for plant tillering at the second harvest, and for total root length and total root surface. Tillering was significantly affected by $\mathrm{N}$ and $\mathrm{K}$ rates at the first harvest. Specific root length and specific root surface was significantly influenced by the supply of $\mathrm{N}$ as well as by $\mathrm{K}$ rates.
\end{abstract}

Key Words: Panicum maximum, root, specific root length, specific root surface, total root length, total root surface

\section{Introdução}

O atendimento das exigências nutricionais das plantas forrageiras é um dos fatores que interfere na produção e na qualidade de forragem das pastagens. Quanto aos nutrientes, o nitrogênio $(\mathrm{N})$ e o potássio $(\mathrm{K})$ estão entre os mais extraídos e têm merecido destaque em relação às plantas forrageiras. $\mathrm{O} \mathrm{N}$ é componente essencial de aminoácidos e proteínas, ácidos nucléicos, hormônios e clorofila, dentre os compostos orgânicos essenciais à vida das plantas e o K está envolvido em diversas reações bioquímicas necessárias ao metabolismo vegetal.
O desenvolvimento vegetativo de uma gramínea é caracterizado pelo aparecimento e desenvolvimento de folhas e perfilhos, alongamento do colmo e desenvolvimento do sistema radicular (Silsbury, 1970).

Vários estudos têm comprovado a influência do estado nutricional da planta forrageira no perfilhamento e em outros atributos morfológicos, como a área foliar. Santos et al. (1995), cultivando o capim-vencedor sob doses de N, constataram que o perfilhamento das plantas diferiu acentuadamente entre as condições de baixo e alto fornecimento do nutriente. Colozza (1998) observou que o número de perfilhos variou

\footnotetext{
${ }_{1}^{1}$ Parte da dissertação de mestrado apresentada pelo primeiro autor à USP/ESALQ, apoiada pelo CNPq.

2 Pós-graduando USP/CENA. Av. Centenário, 303, CEP: 13400-970 - Piracicaba, SP. E.mail: jilavres@yahoo.com.br

${ }^{3}$ Professor Titular do Departamento de Solos e Nutrição de Plantas, USP/ESALQ. Caixa Postal 09, CEP: 13418-900 - Piracicaba, SP. E.mail: famontei@esalq.usp.br; Bolsista CNPq.
} 
significativamente com as doses de N, nos dois cortes efetuados no Panicum maximum Jacq. cultivares Aruana e Mombaça. Para o capim-aruana obteve o maior número de perfilhos com as doses de $\mathrm{N}$ de 150 e $233 \mathrm{mg} / \mathrm{kg}$ de solo, respectivamente no primeiro e segundo crescimentos das plantas, enquanto no capim-mombaça esse aumento no perfilhamento correspondeu às doses de $\mathrm{N}$ de 149 e $268 \mathrm{mg} / \mathrm{kg}$ de solo, também no primeiro e segundo crescimentos, respectivamente.

Pereira (2001) avaliou o efeito do fornecimento de K na solução nutritiva para o perfilhamento e produção de área foliar do capim-mombaça e constatou que as doses de K tiveram efeito significativo no número de perfilhos e na área foliar, em dois períodos de crescimento da gramínea. O autor verificou ainda que o maior número de perfilhos foi obtido com dose de $\mathrm{K}$ igual ou superior a $234 \mathrm{mg} / \mathrm{L}$, no final do primeiro crescimento, e igual a $468 \mathrm{mg} / \mathrm{L}$, no final do segundo crescimento. Para a área foliar constatou-se também que os resultados ajustaram-se a regressão linear, tanto no primeiro como no segundo cortes, demonstrando que a área foliar poderia ser mais elevada, caso as doses excedessem às empregadas.

O crescimento e o desenvolvimento do sistema radicular das plantas sofrem grande influência das condiçõesambientais, porémadisponibilidade denutrientes exerce papel fundamental sobre ambos os parâmetros.

De acordo com Voorhees et al. (1980), o conhecimento das respostas dos vegetais ao seu ambiente tem sido predominantemente restringido a estudos somente da parte aérea em função das dificuldades existentes para investigações do sistema radicular. No entanto, os autores destacaram que a massa seca de raízes é um atributo fácil de ser obtido, em relação a resultados de comprimento do sistema radicular, porém somente a massa seca dessas raízes não expressa a extensão que um dado volume de solo é explorado pelo sistema radicular.

O diâmetro das raízes determina o comprimento radicular que a planta pode produzir. Em condições de baixo fornecimento de nutrientes as plantas produzem raízes muito finas (maior comprimento específico), podendo ser demonstrado pela mensuração direta do diâmetro radicular ou pela determinação do comprimento específico das raízes, que é definido como o comprimento das raízes por unidade de massa seca do sistema radicular (Fitter, 1996).

Maizlish et al. (1980), em um estudo com plantas de milho, determinaram o efeito do fornecimento de doses de $\mathrm{N}(0 ; 21 ; 42 ; 105$ e $210 \mathrm{mg} / \mathrm{L})$ na solução nutritiva. Concluíram que, após três dias da emergência, as diferenças no comprimento das raízes foram pequenas, porém significativas. Aos 10 dias após a emergência das plantas, o comprimento total das raízes na dose de 21 e $210 \mathrm{mg} / \mathrm{L}$ aumentou em 80 e $200 \%$, respectivamente; aos 17 dias após a emergência a diferença entre as plantas que receberam a mais baixa dose para as que receberam a mais alta dose foi de $127 \mathrm{~m}$ de raízes.

Ferrari Neto et al. (1994) avaliaram as limitações nutricionais do capim-colonião e do capim-braquiária cultivados em um Latossolo Vermelho-Escuro distrófico e observaram que, na omissão de $\mathrm{N}$ e K, a produção de massa seca da parte aérea foi afetada significativamente nos dois crescimentos das plantas, bem como a produção de massa seca de raízes. Observaram que no capim-colonião o efeito foi mais drástico por não haver rebrota e para o crescimento das raízes o K mostrou-se mais limitante, salientando que na condição de sua omissão as raízes eram muito finas e frágeis, rompendo facilmente durante a retirada dos vasos e nas sucessivas lavagens.

Partindo-se da hipótese de que o $\mathrm{N}$ e o K interagem no incremento da produção da parte aérea e do sistema radicular das gramíneas, objetivou-se avaliar os efeitos de combinações de doses desses nutrientes em solução nutritiva no perfilhamento, na produção de área foliar e em atributos morfológicos do sistema radicular do capim-mombaça.

\section{Material e Métodos}

O experimento foi realizado em casa-de-vegetação localizada na Escola Superior de Agricultura "Luiz de Queiroz" - USP, em Piracicaba, São Paulo, com a planta forrageira Panicum maximum Jacq. cultivar Mombaça, desenvolvida no período de novembro de 2000 a fevereiro de 2001.

As sementes da gramínea forrageira foram semeadas em bandejas plásticas contendo areia lavada e foram periodicamente regadas com água desionizada. Aos 12 dias após a semeadura, quando as plântulas alcançaram cerca de $4,0 \mathrm{~cm}$ de altura, procedeu-se o transplante de 15 mudas para cada vaso plástico com diâmetro de $17 \mathrm{~cm}$ e volume de 3,6 litros, contendo sílica como substrato. Um dia após o transplante das mudas foi fornecido um litro de solução diluída a $25 \%$ da dose correspondente a cada combinação de $\mathrm{N}$ e K. Essa solução nutritiva foi

R. Bras. Zootec., v.32, n.5, p.1068-1075, 2003 
preparada a partir daquela de Sarruge (1975), modificada para as doses estudadas.

Inicialmente as soluções permaneceram nos vasos durante o dia e a noite, sendo circuladas através da sílica quatro vezes ao dia em um período de uma semana, drenadas à noite e fornecidas durante o dia. Foram realizados desbastes periódicos até permanecerem cinco plantas por vaso. Após quatro dias do transplante, as soluções com concentração definitiva foram adicionadas nos vasos e foram trocadas a cada 14 dias.

Aos 36 dias após o transplante efetuou-se o primeiro corte, a uma altura em torno de dois centímetros do colo das plantas, separando-se o material da parte aérea. Aos 29 dias após o primeiro corte realizou-se o segundo, no colo das plantas, procedendo-se a separação da parte aérea da planta com o mesmo critério adotado no primeiro corte, sendo que as raízes também foram separadas da sílica e lavadas com água corrente e água desionizada, utilizando-se um conjunto de peneiras com diâmetro de malha de 0,25 e $1,00 \mathrm{~mm}$. O número total de perfilhos por vaso e a área foliar do capim-mombaça foram contabilizados por ocasião dos dois cortes das plantas, sendo a área foliar determinada em um sistema digital integrador de área.

Foram utilizadas as doses de $\mathrm{N}$ de $28 ; 112 ; 210 ; 336$ e $462 \mathrm{mg} / \mathrm{L}$ e as doses de $\mathrm{K}$ de 19,5; 117; 234; 312 e $429 \mathrm{mg} / \mathrm{L}$ na solução nutritiva, mantendo-se constante a relação nitrato : amônio em 1,8 (64,4\% $\mathrm{NO}_{3}{ }^{-}$e 35,6\% $\mathrm{NH}_{4}^{+}$). Foi empregado o desenho experimental composto central modificado de um esquema fatorial $5^{2}$ incompleto, fundamentado em Littell \& Mott (1975), com as doses de $\mathrm{N}$ e de $\mathrm{K}$, perfazendo um total de 13 combinações (28N e 19,5K; $28 \mathrm{Ne}$ 234K; $28 \mathrm{~N} \mathrm{e} 429 \mathrm{~K}$; $112 \mathrm{~N}$ e $117 \mathrm{~K} ; 112 \mathrm{~N}$ e $312 \mathrm{~K} ; 210 \mathrm{~N}$ e $19,5 \mathrm{~K} ; 210 \mathrm{~N}$ e $234 \mathrm{~K} ; 210 \mathrm{~N}$ e $429 \mathrm{~K} ; 336 \mathrm{~N}$ e $117 \mathrm{~K} ; 336 \mathrm{~N}$ e $312 \mathrm{~K}$; $462 \mathrm{~N}$ e $19,5 \mathrm{~K} ; 462 \mathrm{~N}$ e $234 \mathrm{~K} ; 462 \mathrm{~N}$ e $429 \mathrm{~K}$ ), as quais foram distribuídas segundo o delineamento experimental de blocos ao acaso, com quatro repetições.

Por ocasião do segundo corte da planta forrageira, após a separação das raízes da sílica e lavagem das mesmas, foi retirada uma sub-amostra do sistema radicular, para cada unidade experimental, cortandose vertical e horizontalmente um volume de raízes com cerca de $20 \%$ de massa fresca total (Habib, 1988; Rossiello et al., 1995). Em seguida, essas subamostras foram colocadas em copos plásticos contendo água desionizada e corante para que as partes mais novas e claras fossem tingidas. Posteriormente, as imagens das raízes foram obtidas com o auxílio de scanner e analisadas através do aplicativo SIARCS ${ }^{\circledR}$ (Sistema Integrado para Análise de Raízes e Cobertura do Solo) versão 3.0. Determinou-se a massa seca destas sub-amostras efetuando-se então a correção para o comprimento total e superfície total do sistema radicular em cada parcela experimental, em função da produção total de massa seca das raízes através de uma simples regra de três, de acordo com a metodologia elaborada por Crestana et al. (1994). O comprimento específico e a superfície específica de raízes foram calculados por meio da razão do seu valor total pela massa seca total de raízes de cada unidade experimental.

O material colhido foi colocado para secar em estufa com circulação forçada de ar, à temperatura de $70^{\circ} \mathrm{C}$, até atingir peso constante. Todo o material vegetal foi pesado em balança de precisão e em seguida moído em moinho do tipo Wiley e acondicionado em sacos plásticos.

Os resultados foram submetidos à análise de variância, utilizando-se o programa estatístico $\mathrm{SAS}^{\circledR}$ - System for Windows ${ }^{\circledR} 6.11$ (SAS, 1996). Em função do nível de significância no teste de $\mathrm{F}$ para as doses de $\mathrm{N}$ e K, procedeu-se ao estudo de regressão polinomial (superfície de resposta), por intermédio do procedimento RSREG.

\section{Resultados e Discussão}

Para o número total de perfilhos por vaso do capimmombaça, no primeiro corte, não foi verificadasignificância $(\mathrm{P}>0,05)$ para a interação entre as doses de $\mathrm{N}$ e de $\mathrm{K}$, enquanto no segundo crescimento das plantas observouse significância $(\mathrm{P}<0,01)$ para essa interação.

No estudo dos efeitos do suprimento de $\mathrm{N}$ e K no perfilhamento da gramínea, no primeiro crescimento, foi observado que houve significância para as doses de $\mathrm{N}(\mathrm{P}<0,01)$ e para as doses de $\mathrm{K}(\mathrm{P}<0,05)$. $\mathrm{O}$ perfilhamento foi representado por uma equação de segundo grau (Figura 1), em relação às doses de $\mathrm{N}$, estimando-se que a dose necessária para o máximo perfilhamento foi de $296 \mathrm{mg} / \mathrm{L}$. O efeito das doses de $\mathrm{K}$ no perfilhamento da gramínea, no primeiro crescimento, é apresentado na Figura 2 e pode-se verificar que o maior número de perfilhos foi obtido com o emprego do K na dose de $291 \mathrm{mg} / \mathrm{L}$.

Ferragine (1998) constatou significância $(\mathrm{P}<0,01)$ para a interação entre $\mathrm{N}$ e K quanto ao número total de perfilhos no primeiro corte de Brachiaria

R. Bras. Zootec., v.32, n.5, p.1068-1075, 2003 


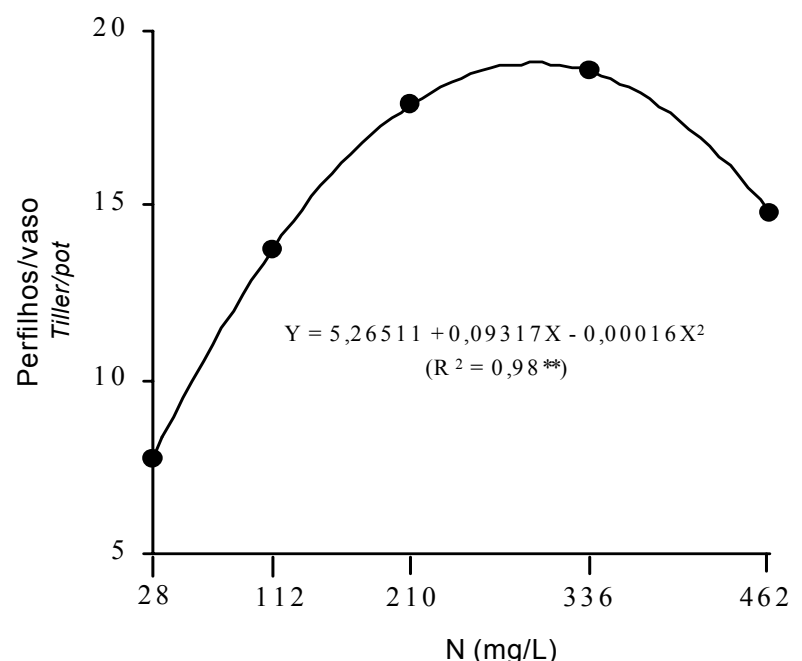

Figura 1 - Número de perfilhos por vaso do capimMombaça, no primeiro corte, em função das doses de $\mathrm{N}$ na solução nutritiva.

Figure 1 - Number of tillers of Mombaçagrass, at the first harvest, as related to $\mathrm{N}$ rates in the nutrient solution.

decumbens Stapf. Verificou também que, em função das doses de $\mathrm{N}$ dentro de cada dose de $\mathrm{K}$, no primeiro crescimento, o número de perfilhos variou com as doses de N, obtendo valor máximo nas doses de 238, 336 e $434 \mathrm{mg} / \mathrm{L}$, dentro da dose de $\mathrm{K}$ de $78 \mathrm{mg} / \mathrm{L}$. Na dose de $\mathrm{K}$ de $390 \mathrm{mg} / \mathrm{L}$ o número de perfilhos foi semelhante entre as doses de $\mathrm{N}$ de 42 e $140 \mathrm{mg} / \mathrm{L}$, não sendo incrementado à medida que se elevaram as doses de 238 a $336 \mathrm{mg} / \mathrm{L}$.

No segundo período de crescimento das plantas (Figura 3) o número de perfilhos foi superior ao encontrado no primeiro. Isto provavelmente ocorreu pelo fato de, no crescimento inicial, a planta concentrar grande parte da energia para o seu estabelecimento, com a formação do sistema radicular e da parte aérea, enquanto no segundo período de crescimento a planta já estabelecida e com maior volume radicular tem a capacidade de absorver maior quantidade de nutrientes, bem como pelo fato de ter sofrido a ação do corte que acaba promovendo a indução das gemas basais, originando os perfilhos. De acordo com a equação de regressão polinomial pode-se constatar que o perfilhamento máximo foi alcançado com o suprimento de $\mathrm{N}$ e $\mathrm{K}$ nas doses de 342 e $396 \mathrm{mg} / \mathrm{L}$, respectivamente.

Estudando os efeitos do suprimento de $\mathrm{Ne} \mathrm{Mg} \mathrm{em}$ solução, para os capins Colonião, Tanzânia-1 e Vencedor, Corrêa (1996) concluiu que o número de perfilhos foi influenciado pelas doses de $\mathrm{N}$, não

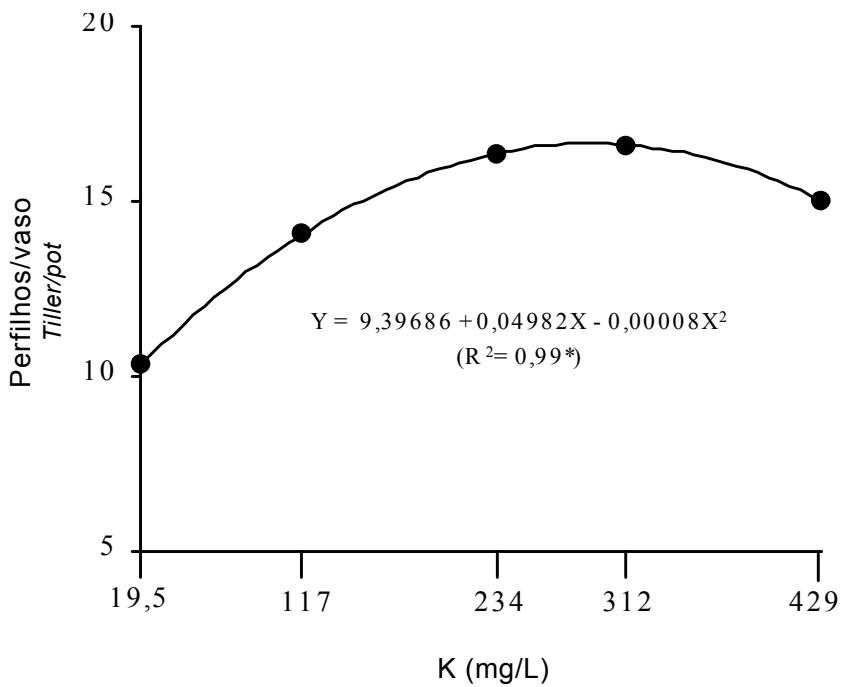

Figura 2 - Número de perfilhos por vaso do capimMombaça, no primeiro corte, em função das doses de $\mathrm{K}$ na solução nutritiva.

Figure 2 - Number of tillers of Mombaçagrass, at the first harvest, as related to $K$ rates in the nutrient solution.

sofrendo efeito significativo das doses de Mg. Tanto no primeiro como no segundo período de crescimento das plantas, o número de perfilhos aumentou da dose de $\mathrm{N}$ de 42 para a de $210 \mathrm{mg} / \mathrm{L}$, mas não variou entre

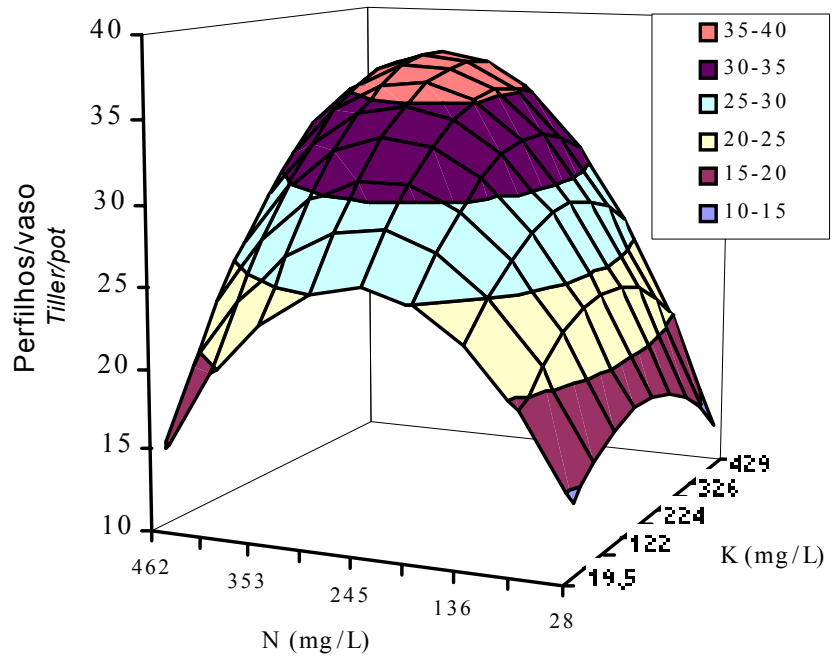

$\mathrm{Y}=10,73857+0,11311 \mathrm{~N}+0,03614 \mathrm{~K}-0,00023 \mathrm{~N}^{2}+0,00012 \mathrm{NK}-$ $0,00009 K^{2} \quad\left(R^{2}=0,78\right)$

Figura 3 - Número de perfilhos por vaso do capimmombaça, no segundo corte, em função das combinações de doses de $\mathrm{N}$ e de $\mathrm{K}$ na solução nutritiva.

Figure 3 - Number of tillers of Mombaça grass, at the second harvest, as related to $N$ and $K$ combinations in the nutrient solution.

R. Bras. Zootec., v.32, n.5, p.1068-1075, 2003 
as doses de 210 e $378 \mathrm{mg} / \mathrm{L}$.

A interação entre $\mathrm{N}$ e $\mathrm{K}$ foi significativa $(\mathrm{P}<0,01)$ para a área foliar total das plantas, no primeiro e segundo crescimentos do capim-mombaça. Por ocasião do primeiro corte, a área foliar total do capimmombaça variou segundo um modelo de equação de regressão polinomial (Figura 4) com o suprimento de $\mathrm{N}$ e K na solução, sendo que nas concentrações mais baixas destes nutrientes a área foliar total foi aproximadamente 11 vezes menor que nas doses de $\mathrm{N}$ e $\mathrm{K}$ de 462 e $429 \mathrm{mg} / \mathrm{L}$. Na combinação das doses mais elevadas de $\mathrm{N}$ e de $\mathrm{K}$, a área foliar total da gramínea foi $22 \%$ maior em relação à área foliar total obtida com o emprego das doses de $\mathrm{N}$ e de $\mathrm{K}$ de 210 e $234 \mathrm{mg} / \mathrm{L}$ (doses usuais da solução completa de Sarruge).

Quanto a área foliar total do capim-mombaça por ocasião do segundo corte, verificou-se interação significativa $(\mathrm{P}<0,01)$ entre as doses de $\mathrm{N}$ e de $\mathrm{K}$ (Figura 5). Foi observado que o valor absoluto de área foliar total produzida no segundo crescimento da planta forrageira foi superior ao primeiro. Comparando-se os dois períodos de crescimento das plantas, a máxima área foliar no segundo corte foi $68 \%$ superior à do primeiro corte. De acordo com os resultados observados, evidencia-se o potencial produtivo desta gramínea em condição de suprimento elevado para tais nutrientes.

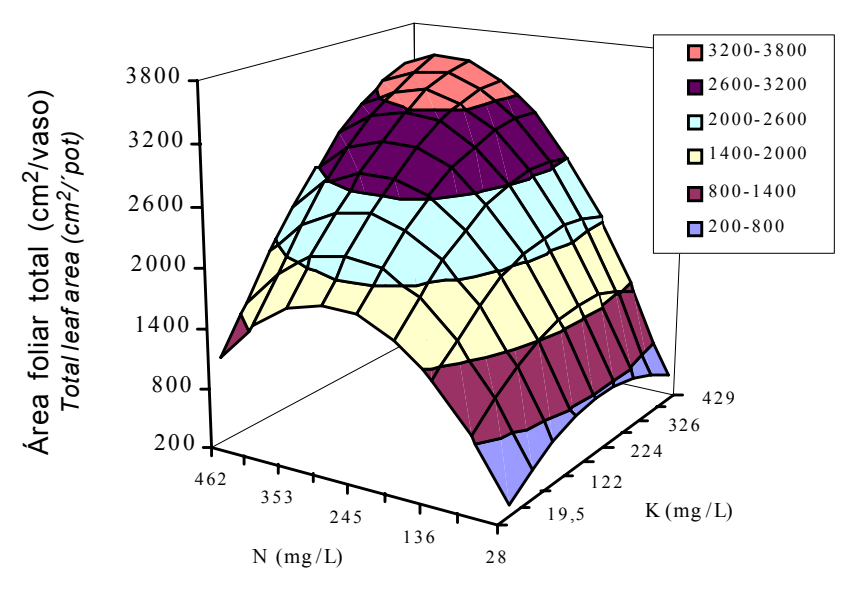

$Y=-135,20784+13,08411 \mathrm{~N}+4,18542 \mathrm{~K}-0,02369 \mathrm{~N}^{2}+0,01217 \mathrm{NK}-$ $0,00908 K^{2}\left(R^{2}=0,88\right)$

Figura 4 - Área foliar total do capim-Mombaça no primeiro corte, em função das combinações de doses de $\mathrm{N}$ e $\mathrm{K}$ na solução nutritiva.

Figure 4 - Total leaf area of Mombaçagrass, at the first harvest, as related to $N$ and $K$ combinations in the nutrient solution.

R. Bras. Zootec., v.32, n.5, p.1068-1075, 2003
Manarin (2000) constatou que a área foliar foi significativamente $(\mathrm{P}<0,01)$ influenciada pelas doses de $\mathrm{N}$ na solução nutritiva, nos dois períodos de crescimento de Panicum maximum Jacq. cv. Mombaça. Pereira (2001), avaliando o efeito do suprimento de K na área foliar total do capim-mombaça, verificou que os resultados ajustaram-se a um modelo linear, tanto no primeiro como no segundo corte, ressaltando que esses valores poderiam ser mais elevados caso as doses empregadas excedessem às estudadas. $\mathrm{Na}$ dose mais elevada de $\mathrm{K}$ e para o primeiro corte da gramínea a área foliar atingiu valor semelhante ao encontrado no presente experimento.

Para os resultados da superfície total (Figura 6) e comprimento total de raízes (Figura 7) do capimmombaça ocorreu significância $(\mathrm{P}<0,01)$ para a interação entre as doses de $\mathrm{N}$ e de $\mathrm{K}$. Através da Figura 6, comparando-se a superfície de raízes na combinação das mais baixas doses de $\mathrm{N}$ e de $\mathrm{K}$ na solução com a combinação das mais elevadas doses foi constatado incremento de seis vezes. A superfície total de raízes nas doses de $\mathrm{N}$ de $210 \mathrm{mg} / \mathrm{L}$ e $\mathrm{K}$ de 234 $\mathrm{mg} / \mathrm{L}$, como na solução de Sarruge (1975), correspondeu a aproximadamente $68 \%$ daquela nas doses mais elevadas de $\mathrm{N}$ e de $\mathrm{K}$.

A interação entre as doses de $\mathrm{N}$ e $\mathrm{K}$ foi significativa $(\mathrm{P}<0,01)$ para o comprimento radicular total do

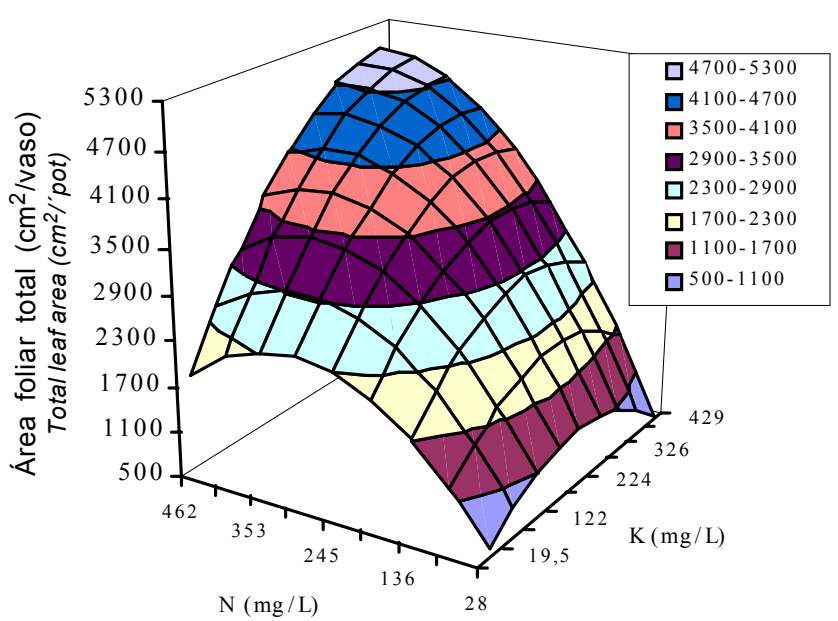

$Y=87,69786+14,00589 N+6,65434 K-0,02384 N^{2}+0,01839 N K-$ $0,01624 K^{2} \quad\left(R^{2}=0,93\right)$

Figura 5 - Área foliar total do capim-Mombaça no segundo corte, em função das combinações de doses de $\mathrm{N}$ e de $\mathrm{K}$ na solução nutritiva.

Figure 5 - Total leaf area of Mombaçagrass, at the second harvest, as related to $N$ and $K$ combinations in the nutrient solution. 


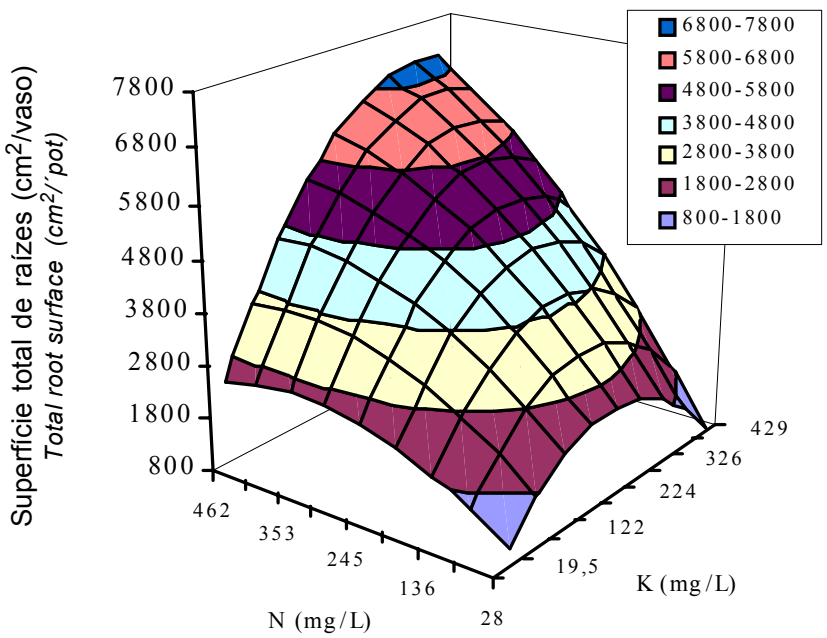

$Y=612,37641+9,50641 N+14,31135 K-0,01467 N^{2}+0,02758 N K-$ $0,03525 K^{2} \quad\left(R^{2}=0,74\right)$

Figura 6 - Superfície total de raízes por vaso do capimMombaça, em função das combinações de doses de $\mathrm{N}$ e de $\mathrm{K}$ na solução nutritiva.

Figure 6 - Total root surface of Mombaçagrass, as related to $N$ and $K$ combinations in the nutrient solution.

capim-mombaça. De acordo com a equação de regressão (Figura 7), constatou-se que para a obtenção do máximo comprimento total das raízes seria necessário o fornecimento das doses de $\mathrm{N}$, na solução nutritiva, mais elevadas que às utilizadas no experimento e de K na concentração de $427 \mathrm{mg} / \mathrm{L}$. Fica evidente que o $\mathrm{N}$ é o principal nutriente modulador das respostas para este atributo produtivo nestas plantas. Observando a dose de K para a máxima expressão do comprimento das raízes, conclui-se que a dose mais elevada supriu a exigência das plantas. Verificou-se também que da combinação das mais baixas doses de $\mathrm{N}$ e de $\mathrm{K}$ para a combinação das mais altas doses, o comprimento das raízes variou de 185 a $912 \mathrm{~m}$ por vaso.

Marschner (1995) relatou que o suprimento de nutrientes pode alterar fortemente o crescimento e a morfologia das raízes. Acrescentou que o efeito é mais marcante para o fornecimento de $\mathrm{N}$ e também que o seu efeito no aumento da área das raízes é freqüentemente mais distinto com o suprimento de amônio em relação ao de nitrato.

Avaliando o desenvolvimento das raízes de duas espécies forrageiras (Holcus lanatus e Deschampsia flexuosa) cultivadas em condição de baixo e alto fornecimento de N, Robinson \& Rorison (1985) cons-

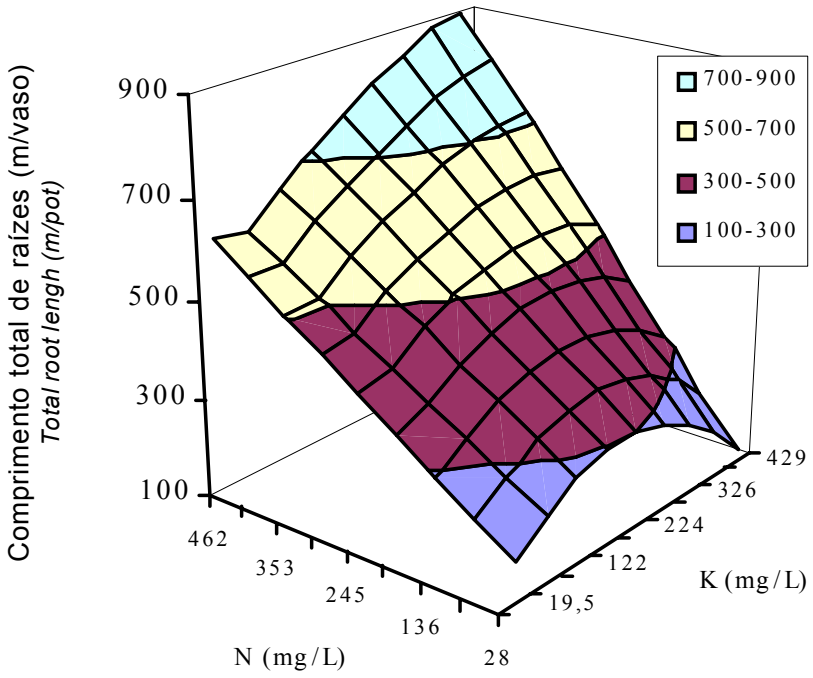

$Y=131,46703+0,98225 N+1,42736 K-0,00183 N^{2}+0,00281 N K-$ $0,00364 K^{2} \quad\left(R^{2}=0,70\right)$

Figura 7 - Comprimento total de raízes por vaso do capim-Mombaça, em função das combinações de doses de $\mathrm{N}$ e de $\mathrm{K}$ na solução nutritiva.

Figure 7 - Total root length of Mombaçagrass, as related to $N$ and $\mathrm{K}$ combinations in the nutrient solution.

tataram diferenças significativas no comprimento total e densidade de raízes em função das adubações, sendo que na Holcus lanatus a densidade de raízes sofreu incremento de forma linear com o suprimento de $\mathrm{N}$.

Para a superfície radicular específica e o comprimento radicular específico não foi significativa $(\mathrm{P}>0,05)$ a interação entre as doses de $\mathrm{N}$ e $\mathrm{K}$ na solução nutritiva, porém verificou-se efeito significativo $(\mathrm{P}<0,01)$ das doses de $\mathrm{N}$ e das doses de $\mathrm{K}$ nestes dois atributos (Figuras 8 e 9).

A superfície radicular específica sofreu variação segundo um modelo quadrático de regressão, com o suprimento de $\mathrm{N}$ e $\mathrm{K}$ na solução. De acordo com as equações de regressão para as doses de $\mathrm{N}$ e K, pode-se constatar que este atributo morfológico atingiu valor mínimo de $342 \mathrm{~cm}^{2} / \mathrm{g}$ com a dose de $\mathrm{N}$ de $291 \mathrm{mg} / \mathrm{L} \mathrm{e}$ $361 \mathrm{~cm}^{2} / \mathrm{g}$ com o fornecimento de $\mathrm{K}$ de $280 \mathrm{mg} / \mathrm{L}$ na solução nutritiva.

Para o comprimento radicular específico foi constatado o mesmo comportamento apresentado em relação à superfície específica, ou seja, à medida que se elevaram as concentrações de $\mathrm{N}$ e $\mathrm{K}$ na solução nutritiva, o comprimento específico foi diminuindo, expressando a indicação do diâmetro médio das raízes ou espessura das raízes (raízes mais grossas) e corroborando com as afirmações feitas por Fitter (1996). 

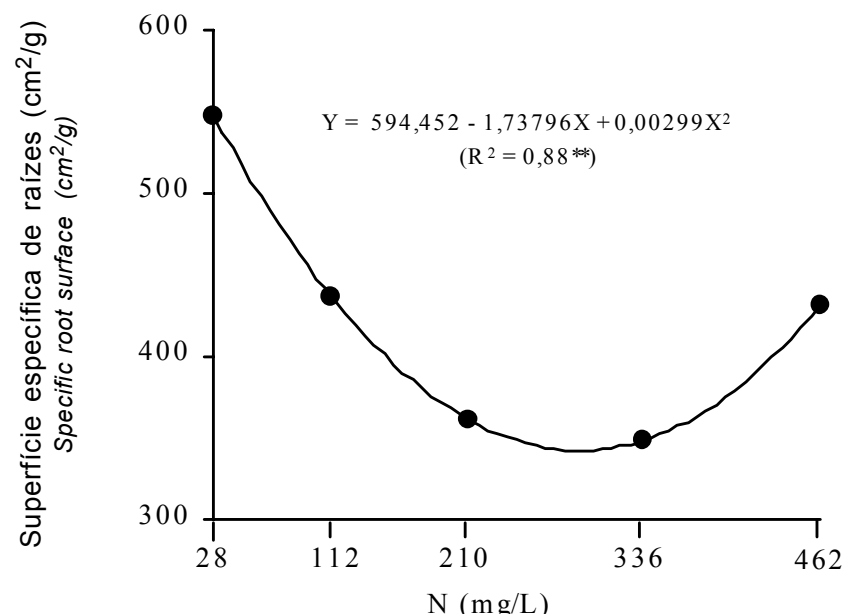

Figura 8 - Superfície específica de raízes por vaso do capim-mombaça em função das doses de $\mathrm{N}$ na solução nutritiva.

Figure 8 - Specific root surface of Mombaça grass, as related to $N$ rates in the nutrient solution.

O comprimento específico das raízes atingiu o menor valor, ou seja, raízes eram mais espessas com a dose de $\mathrm{N}$ de $328 \mathrm{mg} / \mathrm{L}$ e com a de $\mathrm{K}$ de $283 \mathrm{mg} / \mathrm{L}$ (Figuras 10 e 11).

Boot \& Mensink (1990), avaliando o comprimento radicular específico, a área radicular específica e o comprimento radicular de cinco espécies forrageiras (Deschampsia flexuosa, Festuca ovina, Festuca

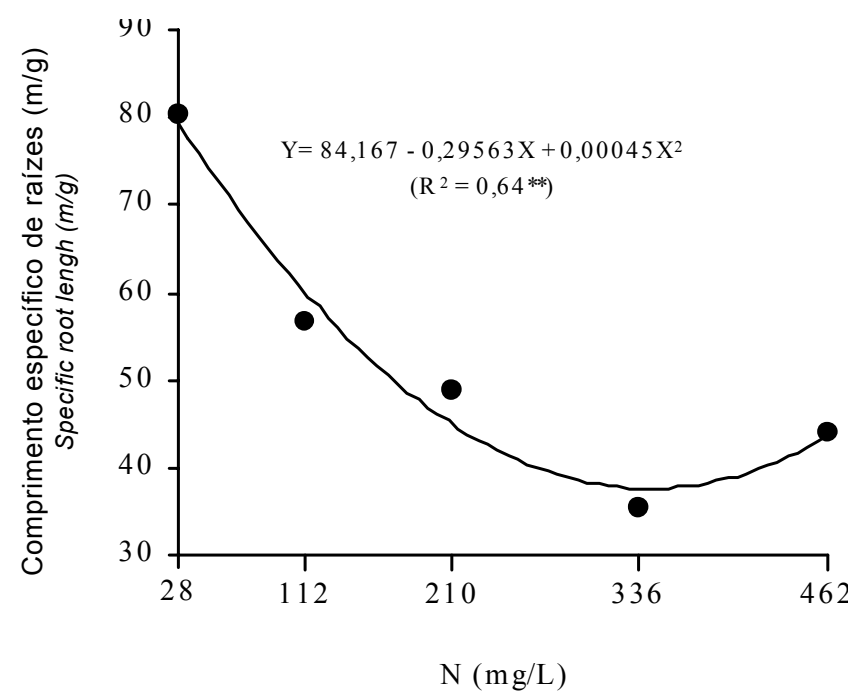

Figura 10 - Comprimento específico de raízes por vaso do capim-Mombaça, em função das doses de $\mathrm{N}$ na solução nutritiva.

Figure 10 - Specific root length of Mombaçagrass, as related to $N$ rates in the nutrient solution.

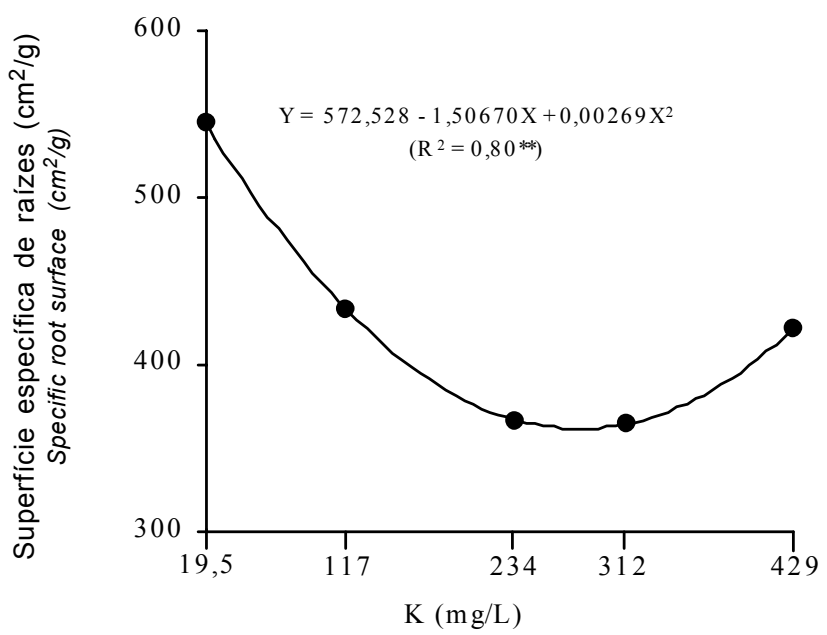

Figura 9 - Superfície específica de raízes por vaso do capim-Mombaça, em função das doses de K na solução nutritiva.

Figure 9 - Specific root surface of Mombaçagrass, as related to $K$ rates in the nutrient solution.

rubra, Holcus lanatus e Molinia caerulea) provenientes de solos férteis e solos com baixa fertilidade e submetidas a duas doses de $\mathrm{N}$, não encontraram diferenças significativas para estes atributos morfológicos com o fornecimento das doses de N. Porém, constataram que as espécies provenientes de solos menos férteis responderam ao baixo suprimento de $\mathrm{N}$ com aumento significativo no comprimento radicular total.

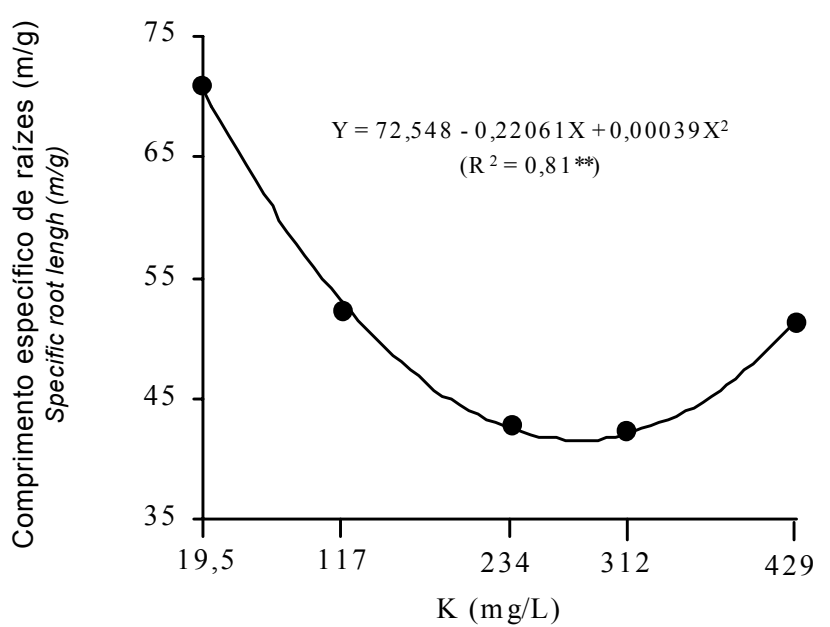

Figura 11 - Comprimento específico de raízes por vaso do capim-Mombaça, em função das doses de $\mathrm{K}$ na solução nutritiva.

Figure 11 - Specific root length of Mombaça grass, as related to $K$ rates in the nutrient solution. 
Santos Jr. et al. (2001) constataram, em pastagens de capim-Tanzânia, que o comprimento específico médio de raízes não variou com o incremento do $\mathrm{N}$ de 150 para $300 \mathrm{~kg} / \mathrm{ha}$.

\section{Conclusões}

As doses de $\mathrm{N}$ e $\mathrm{K}$ interagiram nos dois cortes do capim-mombaça para a produção da área foliar total, comprimento radicular total, superfície radicular total e para o perfilhamento no segundo corte. A superfície total e o comprimento total das raízes do capimmombaça atingiriam valores máximos com o fornecimento de doses de $\mathrm{N}$ e de $\mathrm{K}$ superiores às utilizadas no estudo, destacando principalmente o papel do $\mathrm{N}$ como principal nutriente modulador para estes atributos radiculares. Para o perfilhamento, por ocasião do primeiro corte das plantas, bem como para a superfície radicular específica e comprimento radicular específico do capim-Mombaça, não foi verificada interação significativa entre as doses de $\mathrm{N}$ e K.

\section{Agradecimento}

Ao aluno de Pós-graduação em Solos e Nutrição de Plantas - USP/ESALQ, João de Deus Gomes dos Santos Júnior, pela amizade e ajuda durante a condução do experimento.

\section{Literatura Citada}

BOOT, R.G.A.; MENSINK, M. Size and morphology of root systems of perennial grasses from contrasting habitats as affected by nitrogen supply. Plant and Soil, v.129, n.2, p.291-299, 1990.

COLOZZA, M.T. Rendimento e diagnose foliar dos capins Aruana e Mombaça cultivados em Latossolo VermelhoAmarelo. Piracicaba: Escola Superior de Agricultura "Luiz de Queiroz", 1998.127p. Tese (Doutorado em Solos e Nutrição de Plantas) - Escola Superior de Agricultura "Luiz de Queiroz"/ Universidade de São Paulo, 1998.

CORRÊA, B.D. Doses de nitrogênio e magnésio afetando aspectos produtivos e bioquímicos dos capins Colonião, Tanzânia-1 e Vencedor. Piracicaba: Escola Superior de Agricultura "Luiz de Queiroz", 1996. 76p. Dissertação (Mestrado em Solos e Nutrição de Plantas) - Escola Superior de Agricultura "Luiz de Queiroz"/Universidade de São Paulo, 1996.

CRESTANA, S.; GUIMARÃES, M.S.; JORGE, L.A.C. et al. Avaliação da distribuição de raízes no solo auxiliada por processamento de imagens digitais. Revista Brasileira de Ciência do Solo, v.18, n.3, p.365-371, 1994.

FERRAGINE, M.D.C. Combinação de doses de nitrogênio e potássio na nutrição mineral de capim-braquiária. Piracicaba: Escola Superior de Agricultura "Luiz de Queiroz", 1998. 84p. Dissertação (Mestrado em Solos e Nutrição de
Plantas) - Escola Superior de Agricultura "Luiz de Queiroz"/ Universidade de São Paulo, 1998.

FERRARI NETO, J.; FAQUIN, V.; VALE, F.R. do. et al. Limitações nutricionais do colonião (Panicum maximum, Jacq.) e da braquiária (Brachiaria decumbens Stapf.), em amostras de um latossolo do noroeste do Paraná: I. produção de matéria seca e perfilhamento. Revista da Sociedade Brasileira de Zootecnia, v.23, n.4, p.538-551, 1994.

FITTER, A. Characteristics and functions of root systems. In: WAISEL, Y.; ESHEL, A.; KAFKAFI, U. (Eds.) Plant roots: the ridden half. 2.ed. New York: Marcel Dekker, 1996. p.1-20.

HABIB, R. Total root length as estimated from small sub-samples. Plant and Soil, v.108, n.2, p.267-274, 1988.

LITTEL, R.C.; MOTT, G.O. Computer assisted design and analysis of response surface experiments in agronomy. Soil and Crop Society of Florida Proceedings, v.34, p.94-97, 1975.

MAIZLISH, N.A.; FRITTON, D.D.; KENDALL, W.A. Root morphology and early development of maize at varying levels of nitrogen. Agronomy Journal, v.72, n.1, p.25-31, 1980.

MANARIN, C.A. Respostas fisiológicas, bioquímicas e produtivas do capim-Mombaça a doses de nitrogênio. Piracicaba: Escola Superior de Agricultura "Luiz de Queiroz", 2000. 58p. Dissertação (Mestrado em Solos e Nutrição de Plantas) - Escola Superior de Agricultura “Luiz de Queiroz”/Universidade de São Paulo, 2000.

MARSCHNER, H. Mineral nutrition of higher plants. 2.ed. London: Academic Press, 1995. 889p.

PEREIRA, W.L.M. Doses de potássio e de magnésio em solução nutritiva para o capim-Mombaça. Piracicaba: Escola Superior de Agricultura “Luiz de Queiroz", 2001. 128p. Tese (Doutorado em Solos e Nutrição de Plantas) - Escola Superior de Agricultura "Luiz de Queiroz"/Universidade de São Paulo, 2001.

ROBINSON, D.; RORISON, I.H. A quantitative analysis of the relationships between root distribution and nitrogen uptake from soil by two grass species. Journal of Soil Science, v.36, n.1, p.71-85, 1985.

ROSSIELLO, R.O.P.; ARAÚJO, A.P.; MANZATTO, C.V. et al. Comparação dos métodos fotoelétrico e da interseção na determinação de área, comprimento e raio médio radicular. Pesquisa Agropecuária Brasileira, v.30, n.5, p.633-638, 1995.

SANTOS, A.R.; CORRÊA, B.D.; MONTEIRO, F.A. Efeitos de níveis de nitrogênio sobre o rendimento de matéria seca, teor de nitrogênio e perfilhamento em Panicum maximum cultivar Vencedor. In: CONGRESSO BRASILEIRO DE CIÊNCIA DO SOLO, 25., 1995, Viçosa, MG. Resumos... Viçosa: Sociedade Brasileira de Ciência do Solo, 1995. p.741-742.

SANTOS JUNIOR, J.D.G.; KANNO, T.; MACEDO, M.C.M. et al. Mineral acquisition and utilization strategy of three tropical forages at different phosphorus and nitrogen supply. In: INTERNATIONAL GRASSLAND CONGRESS, 19., 2001, Piracicaba. Proceedings... Piracicaba: Fundação de Estudos Agrários "Luiz de Queiroz", 2001. p.188-189.

SARRUGE, J.R. Soluções nutritivas. Summa Phytopathologica, v.1, p.231-233, 1975.

SAS Institute Inc. SAS/STAT. User's guide, version 6.11. 4.ed., Cary: 1996. v.2, 842p.

SILSBURY, J.H. Leaf growth in pasture grasses. Tropical Grasslands, v.4, n.1, p.17-36, 1970.

VOORHEES, W.B.; CARLSON, V.A.; HALLAUER, E.A. Root length measurement with a computer-controlled digital scanning microdensitometer. Agronomy Journal, v.72, n.2, p.847-850, 1980.

Recebido em: 30/04/02

Aceito em: 17/02/03

R. Bras. Zootec., v.32, n.5, p.1068-1075, 2003 